\title{
A Study of Dental Plaque in Orthodontic Patients
}

Jack W. Balenseifen

Loyola University Chicago

Follow this and additional works at: https://ecommons.luc.edu/luc_theses

Part of the Medicine and Health Sciences Commons

\section{Recommended Citation}

Balenseifen, Jack W., "A Study of Dental Plaque in Orthodontic Patients" (1968). Master's Theses. 2074.

https://ecommons.luc.edu/luc_theses/2074

This Thesis is brought to you for free and open access by the Theses and Dissertations at Loyola eCommons. It has been accepted for inclusion in Master's Theses by an authorized administrator of Loyola eCommons. For more information, please contact ecommons@luc.edu. (c) $($ ) $\Theta \Theta$

This work is licensed under a Creative Commons Attribution-Noncommercial-No Derivative Works 3.0 License. Copyright $\odot 1968$ Jack W. Balenseifen 
A STUDY OF DENTAL PLAQUE IN

ORTHODONTIC PATIENTS

by

Jack W. Balenseifen

A Thests Submitted to the Faculty of the Graduate School of Loyola University in Partial Fulfilinent of

the Requirements for the Degree of

Master of Science

June

1968

IIBRART,

LOYOLA UNVERSITY MEDICAL CWMTER 
ACKNONLEDGEMENTS

I wish to express my sincere gratitude and appreciation to the following.

To John Vincent Madonia, D.D.S., Ph.D., my thesis advisor; for his guidance in preparing this thesis.

To Donald C. Hilgers, B.S., D.D.S., M.S., Chairman of the Department of Orthodontics, who gave me the opportunity to do this work.

To James A. Evans, B.S., D.D.S., M.S., of the Department of Orthodontics, for his encouragement.

To my wife, Winnie, for her love, devotion, encouragement, and secretarial assistance in the preparation of this thesis.

Finally, I want to emphasize the important role of my mother, Pear 1 B. Balenseifen and my father, the late Homer $M$. Balenseifen, for their love, encouragement and help in making this all possible. 


\section{LIFE}

Jack W. Balenselfen was born in Vatonga, Oklahoma on Oetober 20, 1939. He graduated from Watonga High School in June, 1958 and entered Southwestern State college in June of the same year. He graduated from Southwestern State College in August, 1961 with the degree of Bacholar of Sclence.

He entered the University of Missouri at Kansas City, School of Dentistry in 1961 and graduated in June 1965 with the degree of Doctor of Dental Surgery.

He served as a staff dentist with the Oklahoma Public Health Department from 1965 to 1966 . He has been enrolled in the Department of oral Biology at Loyola University working toward a degree of Master of Science since June, 1966. 
TABLE OF CONTENTS

Chapter

Page

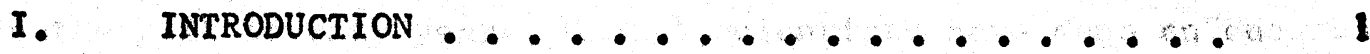

II. REVIEW OF THE IITERATURE ............ 2

A. Microorganisms ............. 2

B. Microorganisms in the oral Cavity ..... 2

C. Microorgansism and Dental Caries ..... 3

D. Orthodontics and Microorganisms . . 7

III. METHODS AND MATERIALS ............ 9

A. Selection of Subject ........... 9

B. Oral Hygiene .............. 9

C. Experimental Procedure ........... 9

D. pH Measurement ............. 10

E. Collection and Welghing the Plaque ...... 11

F. Serial Diluting and Plating ........ 12

G. Carbohydrate Determination ........ 13

H. Statistical Analysis .......... 17

IV. RESULTS ................ 18

A. pH Comparsions ............. 18

B. Carbohydrate Content Comparsions . . . . 19

C. Lactobacillus Content Comparsions ..... 20

D. Streptococcus content comparsions ..... 20

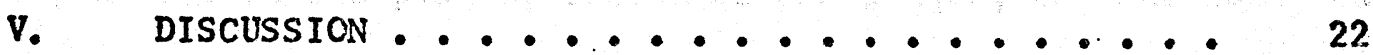

vi. SUMMARY ....................... 30

VII. BIBLIOGRAPHY ................ 31

VIII. APPENDIX ................ 35

A. Figures .............. 35

B. Tables......................... 46 


\section{CHAPTER I}

\section{INTRODUCTION}

In the past seventy years, dental scientists have done an enourmous amount of research on dental caries. The scientists $(5,6,30)$ have found several types of bacteria that are directly related to dental caries. Most dental scientists $(29,30,31)$

believe that the inciplent dental cavity is covered by dental plaque in the beginning of the carlous process. The researchers $(24,30)$ gical point many times, but some research has been done on the composition of the dental plaque in carious and non-carious teeth. The $\mathrm{pH}^{(17)}$ of dental plaque in carlous teeth has been found to be more acidic than the pH of non-carious teeth. The $\mathrm{pH}$ (19) when the patient eats carbohydrates.

The purpose of this thesis is to study changes in the characteristics of the dentai plaque in orthodontic patients. The quanity of jactobacil1i and streptococci in the plaque, the $\mathrm{pH}$ of the plaque, and the total carbow hydrate content of the plaque will be recorded before and after the patim ents teeth are banded. The data will be evaluated for correlations between. content of lactobacil1i and streptococci with the $\mathrm{pH}$ and carbohydrate thest th content of the plaque. atie 
CHAPTER II

REVIEW OF LITERATURE

MICROORGANISMS

The first notable observations on bacteria were recorded in 1675 by Anton Van Leeuwenhoek (1)

a biconvex lens, Ieeuwenhoek discovered bacterla in various body fluids, in water, in peper infusion, in yeast, in beer, and in plaque. The discovery of the microscope opened a new fleld for study of the causation of disease.

Robert Koch ${ }^{(2)} 1843$ - 1910 is conceded to be the "Father of Bacteriological Technic," for he discovered and developed the use of solid culture media, and isolate mixed cultures of microorganisms. He set forth criteria for establishing the etiology of disease. These are known as Koch's postulates and state: (1) A specific organism must always be associated with a disease. (2) It must be isolated in pure culture. (3) Then inoculated into a healthy susceptible animal it must always produce the disease. It should be obtained again in pure culture.

\section{MICROORGANISMS IN THE ORAL CAVITY}

The discovery of microorganism in the oral cavity led to the association of microorganisms with dental caries. In 1872 cutler ${ }^{(3)}$ described the microorganism found in carious dentin of the teeth. Cutler described the microorganism as globular or slipper shaped, measuring $1 / 60,000$ to $1 / 10,000$ of inch in diameter. In 1876 Pierce (4) rods, vibros, and other forms of bacteria taken from carious dentin. 
พ. D. Miller

(5)

1890 compared "Iife conditions" of bacterla in vito with the conditions prevaling in the human mouth and he stated "the oral cavity must be an excellent breeding place for these organlsms."

In 1903 Goadby (6) classifled oral microorganism as liquefiers and acio formers, and he named streptococcus as one of the actd forming organism. KIIgler $^{(7)}$ in 1915 classifled oral microorganisms into three divisions (A) protozoa, (B) spirochetes, and (C) bacterla. He divided the bac1111 of the mouth into anaeroble and aerobic groups.

\section{MICROORGANISMS AND DENTAL CARIES}

In 1884 Underwood ${ }^{(8)}$ observed histologically that microorganisms are always present in carlous lesions and are not present in normal intact tooth substance.

W. D. Miller (5) $1853-1907$ is conceded to be the father of oral nicroblology. As the formulator of the chemico-parasitic theory of dental caries he was the first to appiy a basic science to the solution of dental disease. He described the chemico-parasitic process as twa stages: (A) decalacification and (B) dissolution of the softened residue, He believed that certain microorganisms found in the human mouth possessed the power to produce acid in the presence of food. He never named any one bacterla as the cause of dental decay. In 1897 willams ${ }^{(9)}$ showed that oral acid forming bacteria are the etiological factor in cause of dental decay. K1Igler (10) in 1915 described oral microorganism in material taken from three places: (A) between the teeth, (B) on tooth surfaces, and (C) 
from carious dentin. He belleved that in dental decay the characteristics of the oral flora changed from that of Streptococcus to an acid producing rod. Kligler isolated from the carious material a non-spore forming bac11lus, which he called Bacillus acidophilus, now called Lactobacillus acidophilus. He showed that the bacillus was capable of producing and with standing a greater amount of acid than that produced by any of his other 1solates. In 1922 McIntosh, Janes, and Lazarus-Barlow (11) noted the constant presence of Bacillus acidophilus odontolyticus in carious material: Bunting and Parmerley ${ }^{(12)}$ in 1925 isolated Lactobacillus acidophilus in every initial carious lesion, and they found the organism to be highly pleomorphic. In 1928 Bunting, Nickerson, Hard, and Crowley (13) ran a survey on 1,335 children to find out if there was a correlation between Bacillus acidophilus and dental decay. The group found the correlation to be very high. In 1933 Enxight, Frisell, and Trescher (14) determined that the active agent of carious lesions must be able to withstand a acidity of pH 5.0. They found Lactobacillus acidophilus to be the only microorganism in direct contact with carlous plaque and exhibit both aciduric and acidogenic characteristics at $\mathrm{pH} 5.0$.

In 1941 Fosdick and Starke ${ }^{(15)}$ found that Lactobacilius ecidophlius was able to catalyze the various steps in carbohydrate degradation. Fosdick and Starke notice that lactobacilli accomplished the reduction of pyruvic acid to lactic acid very quickly.

Hemmens, Blayney, Brade1, and Harrison (16) in 1946 studied the cultivable microbial flora of the dental plaque. They found Iactobacillus to 
be the only genus of bacteria for which there was definite evidence of increased incidence with the association of a developing carlous lesion. In 1940 Stephan (17) on tooth and in carious lesions. Stephan stated "The $\mathrm{pH}$ of plaque and open cavities may be lowered by ingestion of certain carbohydrates. These pH changes can be demonstrated directly in the mouth with the antimony electrode.

In 1948 stralfors (18) used an antimony electrode with an electric pH meter, to measure the changes in $\mathrm{pH}$ of the dental plaque and at the same time he made Lactobacillus counts of the saliva. He showed a significant relation to acidic $\mathrm{pH}$ and high Lactobacillus counts. The dental plaque at normal pH had fewer lactobacil1i.

D. E. Jager and Ockerse plaque of tooth surfaces before and after glucose rises by school children In high and low caries incidence area. They found the pH of the saliva to be more acidic in the children with a high incidence of caries, but the $\mathrm{pH}$ of the plaque was not significantly different in the two groups.

Harrison (20) in 1944 studied the plaque of six hundred patients before carles appeared and continued the study on the plaque of three hundred patients which had become carious. He found acid producing and acid tolerating streptococci and lactobacli1i both to be closely related to dental decay.

Besser $^{(21)}$ in 1950 studied plaque material, and he found that lactobacil1i were always present in plaque of carlous teeth. He also noted 
other forms of bacteria in the plaque.

Hemmens, Blayney, Bradel, and Harrison ${ }^{(22)}$ in 1946 found Lactobac11lus was the only bacterium to increase in the plaque with the developing of carious leston.

Irasse ${ }^{(23)}$ in 1954 found that the lactobacilli must be correlated with carbohydrate consumption and carles activity at the same time.

In 1954 orland (24) demonstrated that germ free rats do not develop dental caries even when maintained on diets which are carogenic for their conventional counterpart.

In 1955 orland ${ }^{(25)}$ and his co-workers demonstrated that cerles can be induced in germ free rats infected with combinations of enterococcus and either a proteolytic aerobic rod or an anaerobic pleomorphic rod. A.t Keyes ${ }^{(26)} 1960$, Fitzgerald $^{(27)}$ and Keyes, 1961, and Gibbons (28) 1966 showed that animals harbouring cariogenic bacteria develop bacterial plaques where as little or none accumulate in animals harbouning noncarlogenic bacteria.

Dawes and Jenkins (29) in 1962 found that the dental plaque had a high concentration of calcium and phosphorus in caries high animals. Fitzgerald and Keyes 1960 showed that dental carles was induced in a strain of albino "caries inactive" hamsters by oral inoculation of single or pooled cultures of streptococci isolated from carious lesions in a hamster. He also demonstrated that pooled cultures of six strains of diphtheroid organisms, or six strains of lactobacilli isolated from the 
oral cavity of "caries active" hamsters were without effect when similarly inoculated as were six strains of streptococcl isolated from caries inactive hamsters.

Fitzgerald, Jordan, and Archard (31) 1966 were able to demonstrate that lactobacilli could produce carles in germ free rats when the rats wer fed a diet of coarse particle with high sugar content.

Gibbon and Banghart ${ }^{(32)} 1.967$ using a combination of serologic and isotope dilution technique estimated that dextran comprised almost $2 \%$ of the total dry weight of pooled plaque samples. He spectulated that the plaque had a much higher percentage of dextran in the matrix of plaque.

\section{ORTHODONTICS AND MICROORGANISMS}

In 1948 Oren (33) studied the saliva of his orthodontic patients before and during orthodontic treatment. Owen stated the following: (1) "The presence of orthodontic appliances in the mouth does increase the Lactobacillus count. (2) The degree of increase is dependent some what upon the number of bands. (3) There is a correlation between the total band months and the number of lactobacili1 per cc."

Dikeman $^{(34)}$ in 1962 studied the microorganisras of saliva in orthodontic and non-orthodontic patients. He reported the following: (1) "The presence of stainless steel orthodontic appliances tends to increase both Lactobecillus and Staphylococcus counts but does not appreciably change yeast or streptococcus counts. (2) The greater the milk consumption, the lower the Lactobacillus and yeast counts. (3) A definite positive relationship exists between DMF teeth and Lactobacillus counts." 
Bloom and Brown ${ }^{(35)} 1964$ studied the effect of orthodontic appliances on the oral microbial flora. They measured seven types of microorganisms, including anaerobic and aerobic types. They stated that "all categories showed a numerial increase after the placement of orthodontic appliances, only the lactobacilli increase by a statistically significant amount." The Lactobacillus increase by $3500 \%$ or an average of 90,000 Lactobacillus per milliliter of saliva! They also found "the greatest number of orthodontic bands and auxiliaries manifested the greatest quantItative increase in microbial population studied."

The preceding literature review proves that the orthodontic patient can be used for a study of the dental plaque. The patient can supply a measurable amount of dental plaque, so that bacteriological studies can be done. 
CHAPTER III

METHODS AND MATERIALS

\section{(A) Selection of Subject}

Twenty-one patients between ten and sixteen years of age were selected for this study from the Orthodontic Clinic at Loyola University School of Dentistry. The patients had Class I and Class II (Angle) malocclusion, and they are being treated with light, resillent wires and IIght forces. The patients were checked before the bands were placed, and rechecked one month after the bands and arches were inserted.

(B) Oral Hygiene

The patients were required to brush their teeth for five minutes ustng a Modified Silliman technique (occlusal-gingival cycle). The plaque camples and measurements were collected one hour after the supervised brushing. The patients were not allowed to eat anything during the hour following the brushing. The patients were Instructed to brush their teeth for five minutes using the Modifled Stillman technique after eating. (c) Experimental Procedure

The patients' plaque samples and measurements were recorded one week before the teeth were banded. The $\mathrm{pH}$ of the plaque was recorded in situ. The plaque was then prepared for the Lactobacillus and Streptococcus counting technique. The last test of the plaque samples was the quantitative microdetermination of carbohydrate in the plaque by using the modified anthrone test. 
The second group of plaque samples and measurements were recorded four to five weeks after the bands and arch wires were attached to the teeth. The $\mathrm{pH}$ of the plaque was recorded in situ. The plaque was then prepared for the Lactobacillus and Streptococcus counting technique. The last test of the plaque samples was the quantitative microdetermination of carbohydrate in the plaque by using the modified anthrone test.

The first group of data was recorded before the bands were placed. The second group of data was recorded after the bands and arch wires vere placed. Comparsions were made between the first group of data and the second group of data. The measurements that were compared were (1) $\mathrm{pH}$, (2) Lactobacillus content, (3) Streptococcus mitis content, (4) Streptococcus salivarius content, (5) total Streptococcus content, and (6) Carbohydrate:

(D) pH Measurement

The pH meter was standardized for the two electrodes by using a buffer of known pH solution before each test. Comparative tests were made with the exploring (antimony - silver) electrode and the coleman glass electrode in known $\mathrm{pH}$ solutions at $25^{\circ}$ c. The maximum variation was less than $0.10 \mathrm{pH}$ units in the range of 4.0 to $7.0 \mathrm{pH}$. This variation is comparable with that found by Parks and Beard. (36) Before the Animony silver electrode was used in the mouth, it was standardized with a buffer of pH 6.0 , so that reading could be made directly on the pH scale of the potentiometer - electrometer. 
The pH readings were taken at various sites on the teeth. The plaque was usually found on the buccal of the maxillary molars, 1ingual of the maxillary lateral incisors, lingual of the mandibular molars, and the $1 \mathrm{n}$ gual of the mandibular incisors. A minimum of three readings were recorded for each patient at a session.

A Coleman Metrion IV pH meter was used to read the pH of the patients. The exploring electrode was specially built for this type of pH measurement, and was similar to the one used by stephan ${ }^{(36)}$ in 1940 . It consisted of a glass tube, $z$ " 5 ", which was tappered on one end (Fig. 1). An Antimony - Silver tip was placed at the tappered end of the tube (Fig. 2). The Antimony - Silver tip was cemented with dental compound to the end of the glass tube. A bare copper wire was inserted into the glass tube and the glass tube was then filled with mercury, and the other end of the tube was sealed with dental compound: The exploring electrode was then attached to the pH meter. A standard glass calomel electrode was used for the reference electrode.

The reference electrode was inserted into a saturated solution of potassium chloride. The patient immersed his hand into the potassium chloride, and the investigator inserted the tip of the exploring electrode Into the dental plaque. The $\mathrm{pH}$ reading was then recorded. The tip was the only part of the electrode placed in contact with the plaque. (E) Collecting and Weighing the Plaque 
The plaque was removed from the teeth with a number 6-7 gracy curette. The plaque is placed in a Lily No. 5 gelatin capsules. The gelatin capsules weigh approximately sixteen milligrams after they were reduced in length. The capsules were cut to reduce the welght. The gelatin capsules bere preweighted and placed Into small vials which had the patients name on them. The removal of the plaque from the teeth, and the collecting of the plaque in the gelatin capsule required approximately five minutes. The total welght of the filled capsule is then determined, and the actual weight of the plaque is calculated.

The plaque and gelatin capsule were inserted into a five mililiter Viritis microhomogenizer cup. A recorded quanity of water was added to the plaque and capsule. The plaque to water ratio was approximately three mfl11gram of plaque to one mi11111ter of water. The total capsule was homogenatized in the water at 400 r.p.m. for five minutes. (F) Serial Diluting and Plating

One-tenth of milifiter of the homogenized sample was diluted Into a test tube with nine-tenth of a milliliter of sterile water. The serial difution procedure was continued unt II the sample was diluted to $10^{-15}$. The plating of the diluted sample was done on two different media. The selective media for streptococcl was BBL* MItis-Salfvarius agar. The selective media for lactobacilli was BBL Lactobacillus Selective Agar.* One-tenth of a mililiter of the diluted sample from each of the fourteen tubes of water was placed on the selective streptococci agar. The sample 
was then evenly distributed on the surface of the agar by using a sterile right-angle glass rod. Lactobacillus selective media was heated at $212^{\circ}$ $F$ until it became molten. It was cooled to $53^{\circ} \mathrm{C}$ before using. One-tenth of a milliliter of the diluted sample was placed on the inner surface of a sterile petri dish, and the Lactobacillus selective agar was poured into the dish as the dish was gently rotated. The samples for the lactobacilii selective agar were taken from $10^{-1}, 10^{-2}, 10^{-3}, 10^{-4}$, and $10^{-5}$ dilutions. All of the petri dishes were inverted and incubated for forty-elght hours at $37^{\circ}$ c. The total Streptococci, Streptococcl mitis, Streptococcus salivarius, and Lactobacillus colonies were counted and recorded after the Incubation (Fig. 3 and 4). The streptococcus salivarlus appear on mitis salivarius agar is large, clear, soft, mucold colonies about two to three millimeters in diameter (Fig. 3). The Streptococcus mitis appeared as flat, non-elevated, pin pointed colonies (Fig, 3).

(G) Carbohydrate determination

One mililiter of homogenized sample was pipetted into a tost tube containing five milliliters of anthrone sulfuric acid reagent. One. milliliter of distilled water was pipetted into a second test tube containIng five milliliters of anthrone-sulfuric acid reagent. One milliliter of a glucose-water solution was pipetted into a third test tube containing five milliliters of anthrone-sulfuric acid reagent. The concentration of the glucose-water solution was $0.1 \mathrm{milligram}$ of dextrose per miliiliter of water. The test tubes were gently swirled to mix the reagents with 
the samples. The three test tubes were placed in bolling water for exact1y five minutes. The tubes are removed from the bolling water and placed in an ice-water solution for one minute. The spectrophotometer is set at $620 \mathrm{mu}$. The third test tube was used to callbrate the spectrophotmeter at zero optical density. The first test tube was read first, and the second test tube was recorded last on the spectrophotoneter.

Determining of the carbohydrate content was done by a modification of the technique used by $k$. J. Weeks ${ }^{(37)}$.

The reagent used was a $0.2 \%$ solution of purifled anthrone in $98 \%$ $(v / v)$ sulphuric acid. The reagent solution had a three day shelf life. Five milliliters of the reagent solution were pipetted into a $6 "$ $X 1$ IImless test tube. Overlayed on the surface of the reagent was a one mililiter aliquot of the solution to be analysed. This was done carefully to prevent mixing of the layers. The tubes were then swirled gently to mix the solution and the reagent. The mixture was immediately placed in a boliling water bath for exactly five minutes, where upon it was removed and cooled rapidly to room temperature. The optical density of the solution was determined in a Coleman Model 6135 Junior II Spectrophotoneter at $620 \mathrm{mu}$. where maximum absorption of the color complex occurs.

With each determination, or series of determinations, it was necessary to run a blank which contained one mililiter of water and a standard with one milliliter of a glucose solution containing $100 \mathrm{mg}$. of 
glucose per ml. The amount of carbohydrate in the test solution in term of glucose was calculated as followed: Carbohydrate (as gIucose) per milliliter test solution-

$\frac{\text { Absorbance of test solution - Absorbance of blank }}{\text { Absorbance of std. glucose soln. - Absorbance of blank }} \times \frac{100}{1}$ The relation between color development in the reaction and glucose concentration was linear between 0 and 100 glucose per milliliter and it is not until a concentration of 125 was reached that the deviation from linearity is sufficient to produce an appreciable error. This method gave results accurate to 0.5 microgram consistantly according to Weeks. (37) Because of the strong acid conditions used in the anthrone - carbohydrate reaction, all types of carbohydrate material can be determined directly and the result obtained will always be measure of the total carbohydrate present in terms of the standard sugar solution used. (38) When only one sugar is present then the result can be converted into terms of the sugar by either, applying a correction factor for the difference in color development of the standard sugar and the test sugar, or by using as a standard a solution of the sugar present in the test solution:

The reaction between carbohydrate anthrone under strongly acid conditions produces a blue-green which is specific for carbohydrates. (38) The only other compound which will yield a blue-green color is furfural, but in this case, the color soon becomes brown after a short heating period. (37) 
There are some substances which will produce interfering effects in the determination of carbohydrate in biologival material. Weeks (37) found protein and amino acids are the most usually encountered substances which will produce interference. However, interference due to protein does not make itself felt until the sugar content of the sample falls to about five per cent of the protein content. Below this level Weeks states that clarification procedures must be employed to remove the prom tein.

Before the investigator used the modified anthrone techique for determining the carbohydrate content of the plaque the investigator went through a series of trial tests with known values of glucose per milliliter of water. The test was run three separate times. The first test was done with samples containing $0.02,0.04,0.06,0.08$, and 0.10 mill1 gram of glucose per milliliter of water (Fig. 5).

The second test was like the first test, except for one extra test cample. The extra test sanple contained a solution of 0.058 milligram of protein per milliliter water with 0.058 milligram of glucose per milliliter water. This experiment showed that the protein at a 1 : 1 ratio with the carbohydrate had little effect on the accuracy of the test (Fig. 6).

The third test was like the first test, except for two extra test samples. One of the extra test sample was a solution containing 0,058 milligrams of gelatin per milliliter of water and $0.058 \mathrm{milligrams}$ of glucose per milliliter of water. The other extra sample was a solution 
containing $0.275 \mathrm{mil1igrams}$ of gelatin per milliliter of water and 0.045 milligrams of dextrose per milliliter of water. The third experiment showed the protein could be five times as concentrated and not significantIy alter the accuracy of the test (Fig. 7).

(H) Statistical Analysis

The data from the two groups of experiments were collected and prepared for statistical analysis. In the experiment the same group of patlents is subjected to two different situations. The data was obtained as two series of measurements for the same group of individuals, so that the measurements in each series are not independent of, but, in fact, correlated with, each other.

The statistical analysis of the data was done by using the "Related or Pafred Samples" technique. "The ratio of the average difference to the standard error of the average difference is $t=\frac{\bar{d}}{S E_{\mathrm{g}}}$. This rat 10 is distributed in the $t$ - curve with $(N-1)$ degrees of freedom. The $t$ value wás computed and checked for a $1 \%$ and $5 \%$ level of significance. 


\section{CHAPTER V}

\section{RESULTS}

The plaque samples and measurements were collected from twenty-one patlents before banding. Nine of the original twenty-one patients were eliminated from the experiment due to orthodontic complications. The samples and measurements were collected from twelve patients after the orthodontic intervention.

The comparsions of the data were done on the final twelve patients with respect to their recorded measurements. The data appears in Table 1 and Table 2. A tabulation of the individual measurements for the six categories investigated is presented in Table 3. The pH measurement and the carbohydrate content of the plaque are shown graphically in Fig. 8 and Fig. 9. The logarithmetic counterparts of each bacteria category are shown graphically in Fig. 10, 11, 12, and 13.

\section{(A) $\mathrm{pH}$ comparsions}

The mean $\mathrm{pH}$ of the patients' plaque before banding the teeth was 6.8 . The mean $\mathrm{pH}$ of the plaque one month after attaching bands and arch wires was 6.4 . The difference in the mean $\mathrm{pH}$ was 0.4 . The median $\mathrm{pH}$ of the plaque after orthodontic intervention was 0.4 more acidic than the mean $\mathrm{pH}$ of the plaque before banding.

The $\mathrm{pH}$ value was lowered in each of the twelve patients following the orthodontic intervention. This is shown graphically in Fig. 8. 
Patient number eight had the greatest $\mathrm{pH}$ difference. The difference was $0.80 \mathrm{pH}$ units. Patient number one with a difference of $0.10 \mathrm{pH}$ units had the smallest difference.

The before $\mathrm{pH}$ measurement for each patient was paired with the after pH measurement. The difference was calculated for all twelve patients, The ratio of the average difference to the standand ennor of the average difference is $t-\mathrm{S}_{\overline{\mathrm{d}}}^{\overline{\mathrm{d}}} \cdot$ The + value was 8.36 which is statistically signi-

flcant at the $1 \%$ level.

The results of this investigation have established that there is a numerical decrease in the $\mathrm{pH}$ of the dental plaque following the placement of orthodontic appliances.

(B) Carbohydrate content comparsion

The amount of total carbohydrate in the test solution was calculated in terms of glucose. The mean carbohydrate content of the patients? plaque before banding of the teeth was $0.0277 \mathrm{mg} . / \mathrm{mg}$. of plaque, The mean carbohydrate content of the plaque one month after attaching bands and arch wires was $0.377 \mathrm{mg} . / \mathrm{mg}$. of plaque. The mean carbohydrate content of the plaque was $0.0100 \mathrm{mg} . / \mathrm{mg}$. of plaque higher after attaching the bands and arch wires for one month.

The carbohydrate content of the dental plaque increased in nine of the twelve patients (Fig. 9). The highest increase was $0.0347 \mathrm{mg}$. of plaque. The highest decrease was $0.0127 \mathrm{mg}$. of carbohydrate per $\mathrm{mg}$. of 
plaque (Table 3).

The before carbohydrate content for each patient was palred with the after carbohydrate content. The difference was calculated for all twelve patients. The + value was 2.35 which was not statistically significant at the $1 \%$ level, but it was statistically significant at the $5 \% 1$ evel. This investigation has shown that there is a statistically significant increase In the carbohydrate content of the dental plaque after insertion of orthodontic appliances.

(c) Lactobacillus content comparsion

The mean Lactobaclilus content of the plaque in the before sample was $4.35 \times 10^{2}$ lactobaci11i/mg. plaque. The mean Lactobaclilus count in the after sample was $9.81 \times 10^{4}$ lactobac111i/mg. of plaque. The mean Lactobacillus count in the after sample was $9.80 \times 10^{4}$ lactobacili1/mg. plaque higher than the before sample.

The Lactobacillus count of the plaque increased in eleven of the twelve patients after the placement of orthodontic appliances (Fig. 10). The highest increase in Lactobacillus count was in patient number ten. The increase was $4.98 \times 10^{4}$. Patient number two with an increase of 9.0 $X 10^{1}$ had the smallest increase in Lactobacillus content (Table 3 ).

The before Lactobacillus count was statistically analysed with respect to the after Lactobacillus count. The + value was 6.33 which is statistically significant at the $1 \%$ level.

(D) Streptococcus content comparsion 
Each of the streptococci categories studied manifested an increase in its population mean after the placement of orthodontic appliances (Table 1). The Streptococcus mitis showed the greatest increase of the streptococci. The mean Streptococcus mitis increase was $1.50 \times 10^{14}$ ce11s/mg. of plaque.

The Streptococcus mitis content of the plaque increased in all twelve patients (Fig. 11). Patient number four had the largest increase in Streptococcus mitis. The increase was $1.12 \times 10^{15}$. Patient number two with an increase of $1.13 \times 10^{5}$ had the smallest increase (Table 3 ). The Streptococcus mitis increase was statistically significant $(P<0.01)$. The Streptococcus salivarius content of the plaque increased in eleven of the twelve patients (Fig. 12). Patient number one with an increase of $1.16 \times 10^{12}$ had the largest increase. Patient number eight with a decrease of $5.8 \times 10^{7}$ was the only patient to have a decrease in Streptococcus salivarius content (Table 3 ). This increase in the streptococcus salivarius was found to be statistically significant $(P<0.01)$. The total streptococcl content of the dental plaque increased in all twelve patients (Fig: 13). The increases varied from $1,16 \times 10^{15}$ to $1.12 \times 10^{15}$ (Table 3 ). The increase in the total streptococci was found to be statistically significant $(P<0.01)$. Although all bacterial categories manifested a $r$ ise in population concurrent with the placement of appliances, the total streptococci were found to increase by a far greater amount than any other category: 
CHAPTER VI

DISCUSSION

In any attempt to understand the fundamental nature of dental caries, one is confronted by the question. "What is the mechanism by which enamel and dentin are dissolved from teeth, under the conditions that exist in the mouth?"

The mass of evidence which led W. D. Miller

to formulate the "chemicoparasitic" theory of caries offers a logical starting point for seeking an enswer to this question. We may summarize his findings and theory thus: Caries is a process of dissolution of the calcium salts from enamel and dentin by acids, formed in the mouth by fermentation of carbohydrates by bacteria lodged on tooth surfaces. This process is followed by disintegration of the organic matrix by proteolytic action of the same or other bacteria.

Miller's experiments did not simulate beginning caries of enamel. His experiments did not seem to explain why the acid produced on tooth surfaces was not neutralized by saliva. To fill this gap in the chemicoparasitic theory, others conceived of a "plaque" or "film" on the tooth surface which confined acid to the tooth surface and prevented neutrallzation by saliva.

Willians (39) demonstrated adherent bacterial plaques on surfaces of teeth, including some with beginning caries of the enamel. Black $(40)$, presented evidence of "gelatinous plaques" produced by gelatinizing 
bacteria on those surfaces of teeth which were not cleaned either by a brush or in mastication.

Kirk $^{(41)}$ presented evidence that mucin was precipitated from the saliva to form a "mucin plaque."

Regardless, however, of whether the nature of the ceries producing "plaque" is bacterial, gelatinous, mucinous, composed of food particles or any combination of these, theoretically it is necessary for the plaque to develop a sufficient hydrogen-ion concentration to dissolve enamel, In order for the carlous lesion to develop.

There have been many investigations of the factors governing the solubility of the enamel. Mcclelland, (42) and Staxke, (15) Tresher, (43) Kanthak, (44) Chase, (45) and others have all Indicated that the hydrogen-ion concentration is the chief factor in the solubility of emame1. The evidence indicates that, in a solution containing as much calcium phosphate as saliva, the enamel will ngt dissolve dbove a pH of about 5.0 to 5.5, but will dissolve below this pho since the $\mathrm{pH}$ of saliva is almost always from 6.0 to 7.8 , it is obvious why the saliva does not dissolve enamel. Since enamel is dissolved in baginning carles, it would seem logical that something on the enamel surface attains a pH less than $5.0-5.5$. The measurenent of this $\mathrm{pH}$ is important in oxdex to determine the immediate activity of the carious process. There are several methods of measuring $\mathrm{pH}$, none of which is without some disadvantages. 
The microcolorimetric technic used by stephan ${ }^{(17)}$ in a reported study shored variations in $\mathrm{pH}$ of plaques from 4.6 to 7.0 , and the carlous debris from 4.2 to 7.0. This method required considerable time and patlence, and therefore it was difficult to make many tests on material from tooth surfaces at one time. The material tested was removed from the mouth, and only one measurement was possible:

Electrometrle methods have proved applicable for repeated direct measurements of $\mathrm{pH}$ in vivo. The glass electrode has the fewest errors. Microglass electrodes small enough to be applicable for pH readings on tooth surfaces have two serious liminations: 1. The electrodes are very fragile, and they break with slight pressure. 2. Their electrical resistance is so high that thorough electrostatic shielding is necessary. Thus far, these limitations have hindered their use directly on tooth surfaces. The antimony electrode has neither or these Iimitations.

Parks and Beard (36) have shown that a polished stick electrode, in the presence of air, and with a vacuun tube potentiometer-electiometer which would prevent polarization of the electrodes, followed the theoretical Nernst equation from $\mathrm{pH} 2-7$ at $25^{\circ} \mathrm{C}$, the greatest diviation being $0.2 \mathrm{pH}$ unit.

T. $R_{\text {. Ball }}{ }^{(46)}$ showed that an antimony sulfide electrode functions between $\mathrm{pH} 1.8 \mathrm{pH} 10$, with results reproducible to $0.09 \mathrm{pH}$ unit. citrates rendered the electrode useless, but 10 per cent sugar, 2 per cent starch 
and 0.5 molar sodiun nitrate were without effect:

For many years acids produced by microorganisms have been considered a causative factor of dental caries; in fact even today this theory influences dental caries research to a very great extent. It seems reasonable to assume that, if it is correct, the acidity could be measured, the pH determined, and a fall in pHt the critical pH or beyond should be demonstrated in dental plaque or in carlous cavities.

The caries research done on gnotobiotic rats by orland (24) 1954 showed that germ free rats do not develop dental caries even when maintained on diets which are cariogenic for their conventional counterpart. Fitzgerald ${ }^{(27)} 1960$ demonstrated the etiologic role of streptococci in experimental carles in the hamster. Recently, Oxland (47) 1964 reported that oral lactobacilli of human origin became cariogenic for rats af ter being maintained in three successive generation of gnotobiotic rats. The active role of lactobacil1i and streptococci in dental caries vas one of the reasons for selecting these microorganisws to be measured in the experiment.

The Author's experiment showed that the $\mathrm{pH}$ of the plaque became nore acidic after the orthodontic intervention. The plaque became more acidic due to a quantitative increase of bacteria content and a quantitative increase of carbohydrate content of the plaque. The streptococel and the lactobacilli content both had a quantitative increase in the plaque. These two groups of bacteria are acid producing and acid tolerating in 
character: The quantitative Increase in carbohydrate content provide these bacteria with more substrate for degradation.

The data from the experiment showed that both the streptococci and the lactobacilli content of the plaque had a quantitative increase. It is quite conceivable that the inherent irregularities of fixed orthodontic appliances could, in general, provide additional surfaces for the collecttion and retention of food debris. These additional surfaces would contribute more area of environment suitable for the growth of bacteria. In this respect, Omisi and Kondo ${ }^{(48)}$ found that placing a plastic plate on the palate increase the number of lactobacil11 within a few days. They postulated that fermentation areas can lead to an increase in lactobacil1i

It is a well known fact that lactobacilli grows better in an acldic medium. It is possible that the increase in streptococcl content will provide a more acidic plaque, which will be a better medium for the growth of lactobac1111. The increase in the carbohydrate content of the plaque will provide a more suitable environment for streptococel, which In turn provides a more suitable environment for the lactobacilit. Harrison (20) In a study of dental plaque from carlous teeth always found acld producing and acid tolerating streptococel with lactobacil11.

A comparsion was made of the lactobacil11 and streptococci content of the plaque with the $\mathrm{pH}$ of the plaque. There was an increase in lactobacl111 and streptococci content with an increase in acialty. There was no linear correlation of the increase in bacteria content and the $\mathrm{pH}$ as a 
group, but the individual samples were postitively related. The reason that the group did not show a linear relationship was due to the tremendous variation in increase of bacteria content with a small change in $p H$. The orthodontic appliances tend to enhance bacterial growth by providing a more suitable environment for bacterial activity and thereby subjecting the oral environment to imbalance and possible disease. It is generally recognized that cariogenic bacteria are able to initiate the formation of dental plaque for it has been a consistent finding that animals harbouring carlogenic bacterla develop bacterla plaque whereas little or none accumulates in animals harbouring non-cariogenic bacteria Keyes $^{(26)} 1960$, Fitzgerald ${ }^{(27)}$ and Keyes, 1961, Gibbons ${ }^{(28)}$ et al, 1966. (49)

Carlsson and Egelbery 1965 observed that sucrose stimulates plaque formation in man. It is possible that the increase of food debris in the area could aid the bacteria in producing dental plaque, and the new plaque could have higher carbohydrate content.

The modified anthrone test for the carbohydrate content of the plaque appears to be very valuable. The test determined the total caxbohydrate content of the plaque with fer limitations. The test is accurate to one millionth of a gram. The accuracy is not altered to any appreciable extent unless the reagent is over three days old.

It is important to note that there is a quantitative increase of the carbohydrate content of the plaque. It is obvious that there is an increase in total plaque after banding which in itself would increase the 
total bacteria count. The increase in carbohydrate content could be due to an increase in dextran which is belleved to be the matrix material for dental plaque according to Gibbons. The Increase in carbohydrate content could also be due to an increase in unattached substrate, or both an increase in dextran and substrate.

The carbohydrate content of the plaque Increased on the average by 40 per cent after the orthodontic Intervention. Eastoe and Bowen 1967 showed that when a few drops of $0.1 \mathrm{M}$ solution of sucrose was placed on the dental plaque, their was a drop in pH to 5.17 (S.D. \pm 0.38$)$ after 20 minutes. Whereas the absolute significance of the measured pH near tooth surface must be interperted with caution, it is considered that the se measurements provide clear evidence for the production of substantial quantities of acid at these sities and strongly suggests its part Icapation in the development of the carious lesions.

It appears from the results of the experiment that the dental plaque must have an increase in carbohydrate content before there is an increase in acidity or bacteria content. The alteration of the oral ervironment is primarly that of increasing the food debris in the dental area due to fixed orthodontic appliances. The increase in bacteria and the increase of acidity of the plaque can increase the carious activity in the oral. cavity. It appears that this chain of ovents could be retarded by instigating good oral hygiene in these patients. Proper oral hygiene would ellminate the excessive food debris, and the bacterial environment would 
be favorable alter.

There was no 1 inear relationship between the carbohydrate content and the bacteria content of the plaque. The change in each group was statistically significant with respect to measurement made before and after orthodontic intervention, but there was no linear relationship between the two due to the large variation of bacteria with a simultaneous srall change in carbohydrate.

It is important to note that in this experiment the measurements were of the concentration of the carbohydrate and the concentration of the bacteria in the plaque. Packed organism (solid bacteria) at the bottom of a centrifuged tube show a concentration of $2.3 \times 10^{14} / \mathrm{Mg}$. This value is approximately the same as the plaque measurement after orthodontic intervention. The results would indicate that there is less other material and more bacteria and carbohydrate in carious plaque.

It is the opinion of the author that further research should be done on the dental plaque after orthodontic intervention. It is possible that the changes seen in the dental plaque after orthodontic intervention are the same as in cariaus plaque. The changes in the plaque of an orthodontic patient are relatively easy to measure, and the patient is reliable and the control of the patient during the experiment is assured. A few of the characteristics that should be measured are the following; protein content, calcium content, phosphate content, and potassium content: 


\section{CHAPTER VI}

\section{SUMMARY}

A comparsion of the quantiative changes of the dental plaque of twe Ive patients, before and after orthodontic treatment, was made. The four microbial populations were measured by plating measured wet plaque samples on standard selective culture media. The pH of the plaque was measured in situ by an exploring glass electrode with an Antimony-silver tip. The carbohydrate content of the plaque was quantiatively measured by using a modified anthrone-sulfuric acid test:

The following results were obtained:

(1) The $\mathrm{pH}$ of the dental plaque became more acidic after the placement of orthodontic appliances. (2) The carbohydrate content of the plaque increased by $40 \%$ after the orthodontic intervention. (3) The Lactobacillus Streptococcus mitis, Streptococcus sallvarius, and total streptococcus quantlative counts showed a numerical increase after the placement of orthodontic appliances. (4) The changes in the pH measurement, carbohydrate content, and microbial population of the dental plaque were all statistically signigicant. 


\section{LITERATURE CITED}

1. Dobe11, C. A., Anthony Van Leeuwenhoek And His Little Animals. New York: Harcout, Brace, and Company, 1932.

2. Bulloch, W. J., The History of Bacteriology. London and New York: Oxford University Press, 1938.

3. Cutler, S. P., Microscopy of Minute Organiso," D. Cosmos, 14: 459461 (Aug) 1872.

4. Pierce, C. N., "The Iower Forms of Life Found Within the Oral Cavity" Penn. I. D. ScI., 3: 1-21 (Jan) 1876.

5. Miller, W. D., Microorganisms of the Human Mouth," Philidelphia: S. S. White Dental Mfg. Co., 1890 .

6. Goadby, K. W. "Mycology of the Mouth," London, New York and Bombay: Iongmans, Green, and Co, 1903 .

7. Eligler, I. J,, "Chemical Studies of the Relations of Microorganisms - to Dental Caries: A Biochemical study and Differentiation of Oral Bacteria with Special Reference to Bental Carles," I. Allied D. Soc. 10: 141-166, 282-329 (June - Sept) 1915.

8. Underwood, A. S., "On the Influences of Microorganisas in the Pro. duction of Caries," Am. J. D. Sci., 18: 83-87, 307-317, 372375 (July) 1884.

9. Willians, J. L., "A Contribution to the Study of Pathology of Enamel, D. Cosmos, 39: 267-301 (Apr - May) 1897.

10. Kligler, I. J., "A Biochemical study and differentiation of oral bacteria with special reference to dental caries," J. Allied D. Soc., 10: 141-166, 282-329, (June - Sept) 1915.

11. McIntosh, J., James, W. W. and Lazarus - Bar1oa, P., , In Investigation into the Etiology of Dental Caries. I: The Nature of Destructive Agent and the Production of Artificial Caries," Brit. D. I., 43: 728-739 (Aug) 1922 .

12. Bunting, R. W., and Parmerlee, F., "Role of Bacillus Acidophilus in Dental Caries," J. A. D. A., 12, 381-411 (Apri1) 1925 . 
13. Bunting, R. W., Nickerson, G., Hard, D., and Growley, M., "Further Studies of the Relation of Bacilius Acidophilus to Dental Carles," D. Cosmos, 70: 1-8 (Jan) 1928.

14. Bnright, J. J., Friese11, H. E., Trescher, M. O., "Studies of the Cause and Nature of Dental Caries," J. D. Res., 12: 759-864 (Oct) 1932.

15. Fosdick, L. S., and Starke, A. C., "Carbohydrates Degradation by Mouth Organisms. Part III Lactobacillus Acidophilus," J. A. D. A., 28: 234-240 (Feb) 1941 .

16. Hemmens, E. S., Blayney, J. R., Bradel, S. F., and Harrison, R. W., "The Microbic Flora of the Dental Plaque in Relation to the Beginning of Caries," J. D. Res., 25: 195-205 (Aug) 1946.

17. Stephan, R. Mo, "Changes in Hydrogen-Ion Concentration on Tooth Surfaces and Carious Lesions," J. A. D. A., 27: 718-722 (May) 1940.

18. Stralfors, A., "Studies of the Microbiology of Caries," I. D. Res., 27 : $576-586$ (Oct) 1948 .

19. DeJager, C. I., and Ockerse, T., "The $\mathrm{pH}$ readings of Saliva and Dental Plaque of Tooth Surfaces before and after Glucose Rinses by School Children in a High and Low caries Incidenoe Area in the Republic of South Africa," J. D. A. S. Africa. 26: 70-73 (March) 1965.

20. Harrison, R, W., MLactobac111i Verus Streptococel in the ztiology of Dental Caries," J. A. D. A., 37:391-403 (oct) 1948.

21. Besser, P. W., "Lactobacillus and Dental Caries," The Medentelan, $2898,106-109$ (May) 1950.

22. Hemmens, E. S., Blayney, J. R., Bradel, S. F., and Harrison, R. W., R. W., "The Microbic Flora of the Dental Plaque In Relation to the Beginning of Carles," J. D. Res., 25, 195-205 (Aug) 1946.

23. Krasse, B., "Relationship between caries activities and the number of lactobacillus in the oral cavity." Acta Odon Scand, 12: 157-172 (Nov) 1954.

24. Orland, F. J., "The use of Germ Free Animals in Study of Experimental Dental Caries," J. D. Res. 33: 147-174 1954. 
25. Orland, F. J., and Others, "Experimental Caries in Germ Free Rats Inoculated with Entercocci," J. A. D. A. 50: 259, (March) 1955.

26. Keyes, P. H., "Infectious and Transmissible Nature of Experimental Dental Carles," Archs Oral Biol. 1: 304-320, 1960.

27. Fitzgerald, R. J., and Keyes, P. H, , "Demonstration of the Etiologic role of Streptococci in Experimental Caries in the Hamster," J. A. D. A. $61,9-31,1960$.

28. Gibbons, R. J., Berman, K. S., Knoettner, P. and Kapsimalis, B., "Dental Caries and Alveolar bone loss in gnotoblotic rats infected with capsule forming streptococci of human origin," Archs Orat B10. 11: 549-560 (1966).

29. Dawes, C., and Jenkins, G. N., "Some Inorganic Constituents of Dental Plaque and Their Relationship to Early Calculus Formation and Caries," Arch Oral Biol 7: 161-172, 1962.

30. Fitzgerald, R. J., Jordon, H. V., and Archard, H. O., "Dental Caries in Gnotobiotic Rats Infected with a Variety of Lactobacillus Acidophilus." Arch Oral Biol 11: 473-476, 1966.

31. Gibbons, R. J., and Banghart, S. B., "Synthesis of Extracellular Dextran by Cariogenic Bacteria and its Presence in Euman Dental Plaque," Arch Oral Bio 12: 11-24, 1967.

32. Owen, 0. W., "A Study of Bacterial Counts (Lactobact 11i) In saliva related to orthodontic appliances," Am. J. Onthodont. 35: 672-678 (Sept) 1949.

33. Dikeman, T. L., "A Study of Acidogenic and Aciduric micxoorganisms in Orthodontic and Non-Orthodontic patients," Abs. Am. J. Orthodont. 48: 627 (Aug) 1962.

34. Bloom, R. H,, and Brown, L. R., "A Study of the effects of Orthodontic appliances on the Oral Microbial Flora," Oral Surg., Oral Med., Oral Path., 17: 658-667 (May) 1964.

35. Stephan, R. M., "Changes in Hydrogen-Ion Concentration on Tooth Surfaces and in Carious Lesions," J. A. D. A. 27, 718: 723 : May 1940.

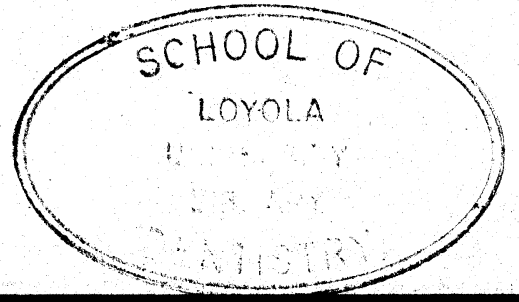


36. Parks, L. R., and Beard, H. C., J. Am. Chem. Soc. 54: 856, 1932.

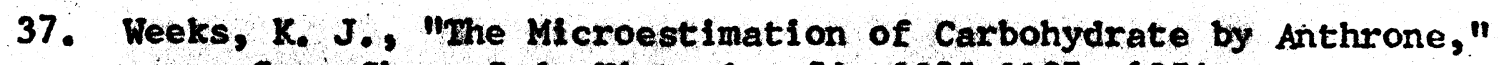
Soc. Chem. Ind. Victoria, 54: 1185-1187, 1954.

38. Dreywood, R., "Ind. Eng. Chem. Anal. Ed.," 18: 499 (1946).

39. Williams, J. I, D. Cosmos 39,269, (ApriI) 1897.

40. Black, C. V., Operative Dent btry, Vo1. I, Chicago; Medico - Denta1 1. publiting 60.620 .

41. Kirk, E. C., D. Cosmos 52: 729-737, (July) 1910.

42. Mccle11and, J, R, , D, Cosidos, 68, 127, (Feb) 1926.

43. Enright, J. J., Frlese11, H. E., and Tresher, M, 0,, J. D. Res. 12 : 759. (Oct) 1932.

44. Kanthak, F. F., J. D. Res. 14,21 , (Feb) 1934.

45. Chase, H. C., I. D. Res. 14: 212, (June) 1934.

46. Ba11, T. R., Tr. Electrochem Soc. 72 : 139 (1937).

47. Orland, F. J. "The Human Teeth and its Environment." J. Den. Res. 43: 1045-1051, 1964.

48. Ontsi, M., and Kondo, W., "Establishing an Environment for growth of Actogenic Bacteria in the Oral Cavity W $^{\text {If }}$ Dent. Res. 35.596 1965.

49. Carlsson, J,, and Egelberg, J,, MEffect of diet on early plaque formation in man." Odont. Revy. 16, 112-125, 1965. 


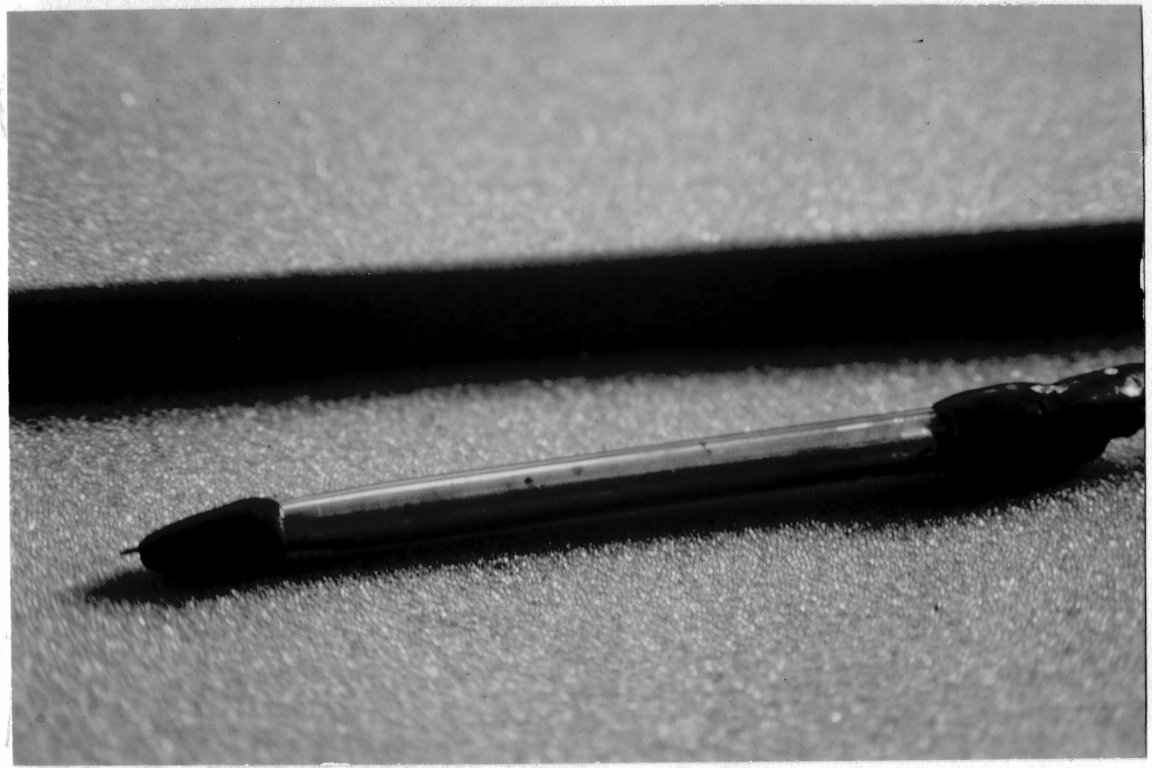

Fig. 1 GIASS EXPLORING EIECTRODE

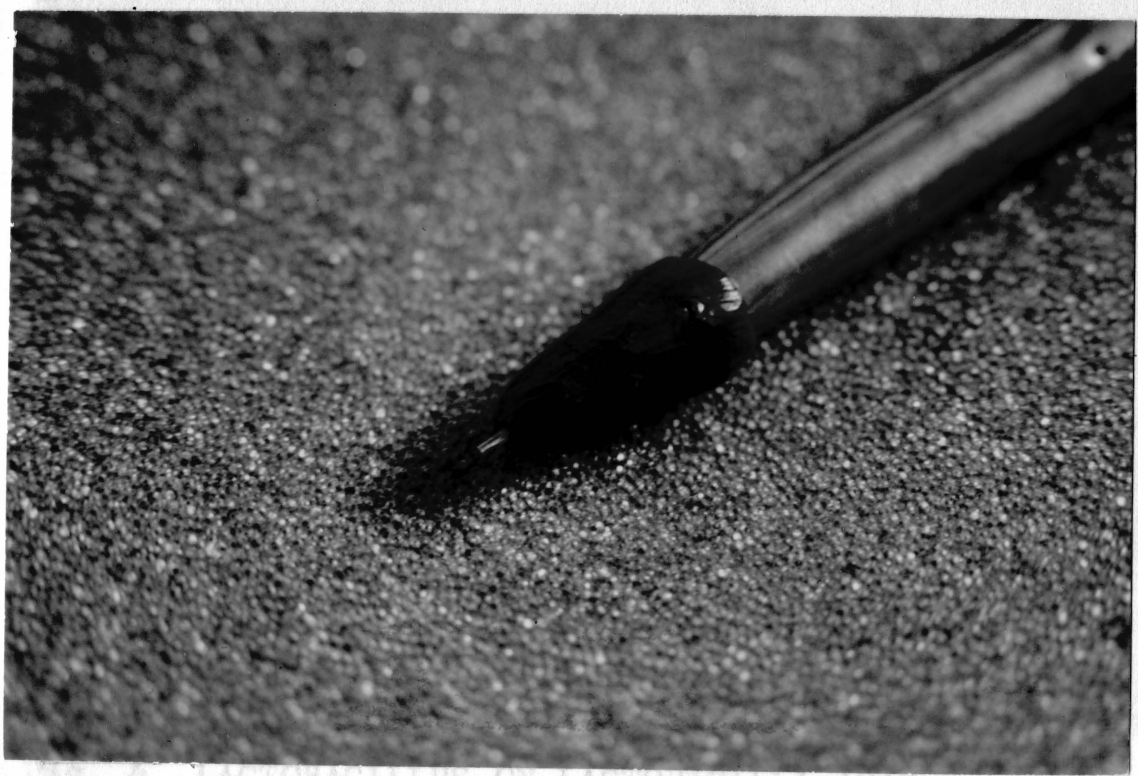

Fig. 2 CLOSE UP VIEN OF ANTIMONY -SILVER TIP 


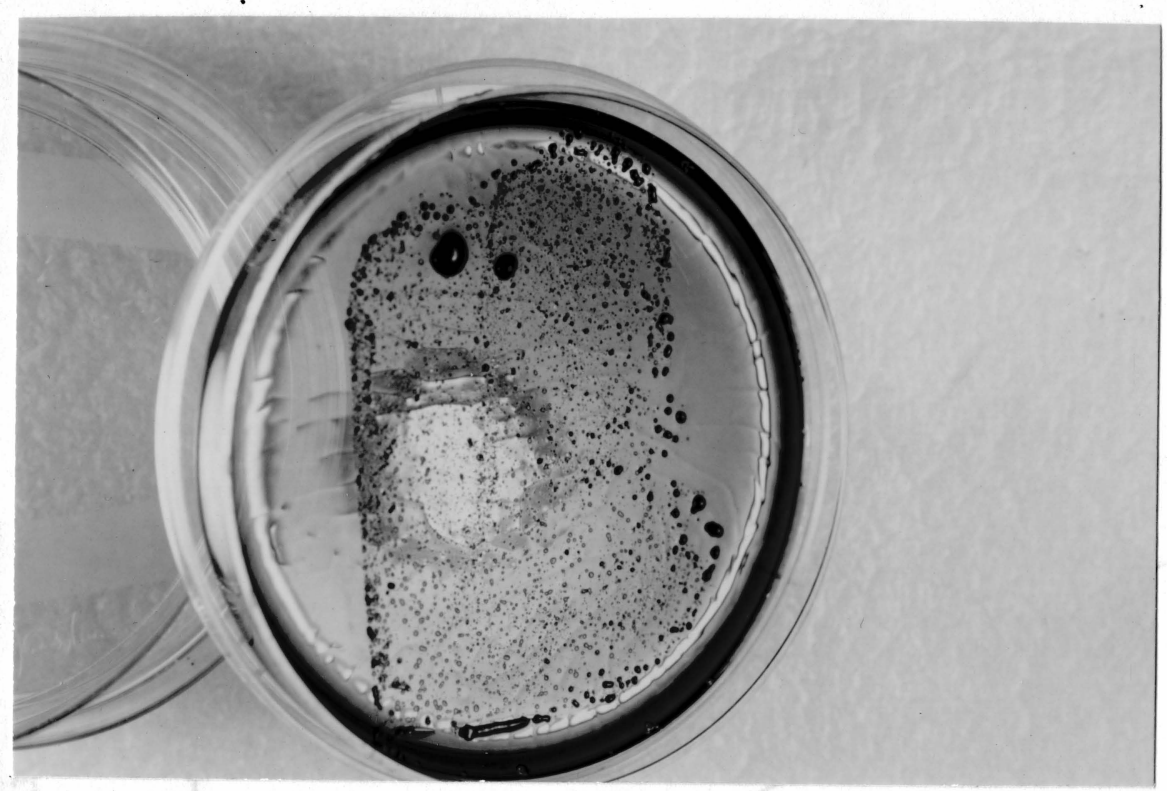

Fig. 3 STREPTOCOCCUS MITIS AND STREPTCCOCCUS SALTVARIUS ON MITIS SALIVARIUS AGAR.

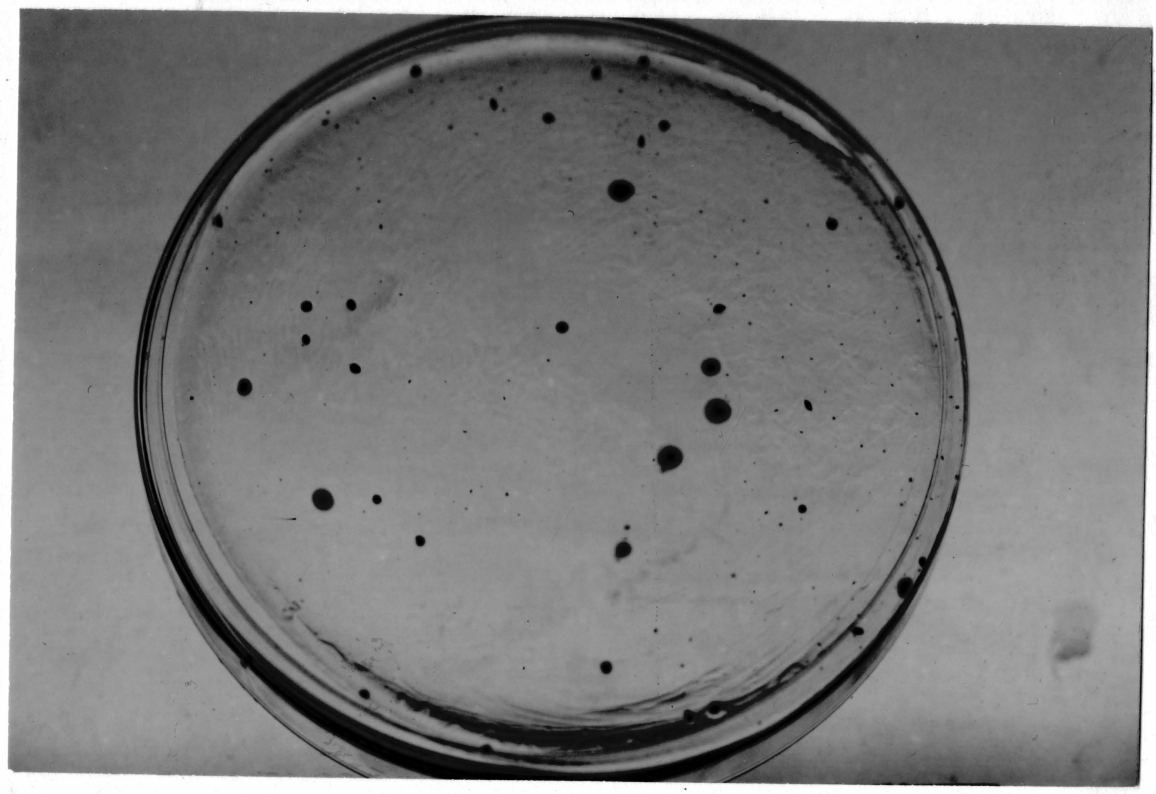

Fig. 4 IACTOBACIILUS ON IACTOBACILII AGAR. 


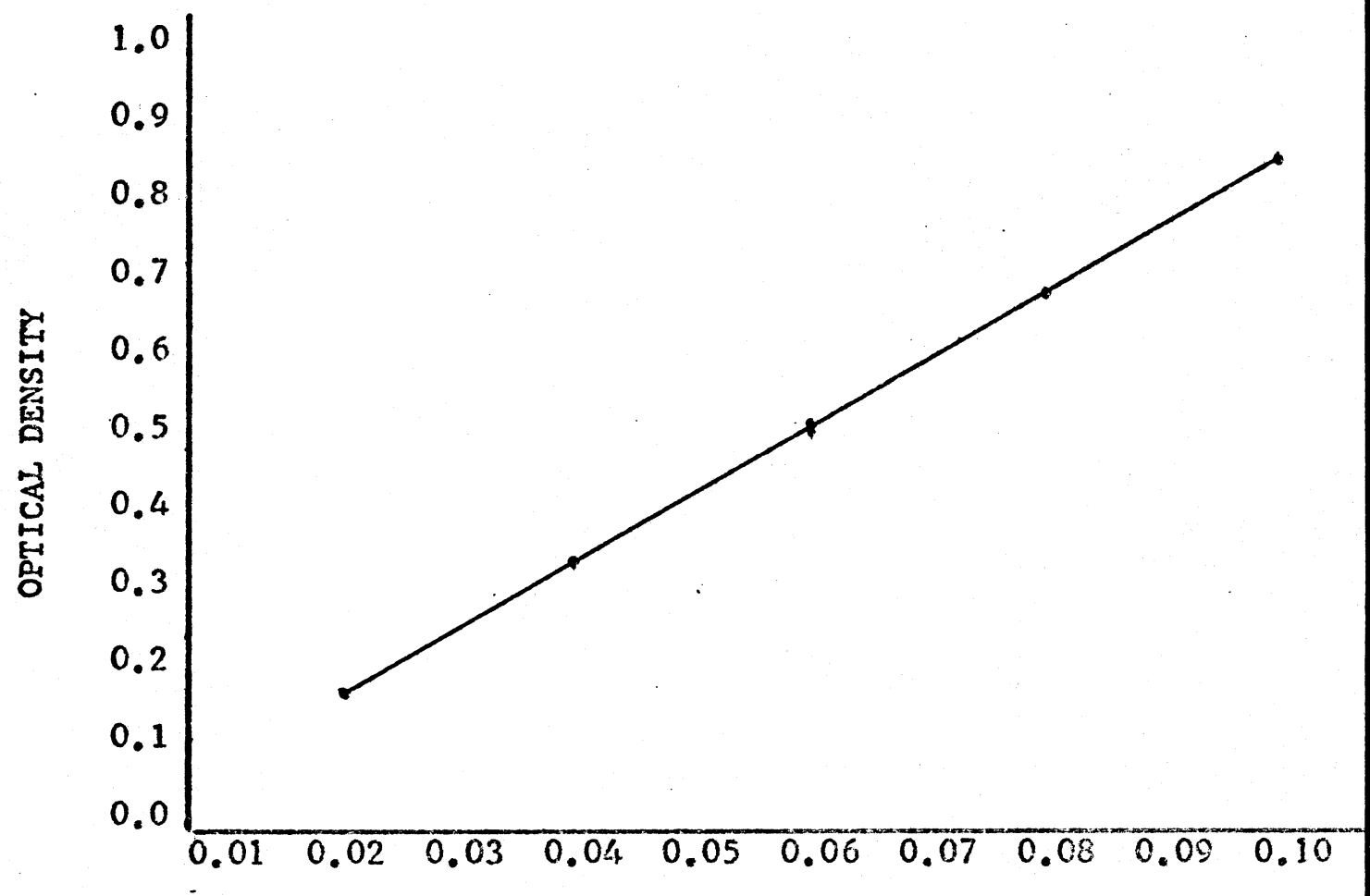

Concentration of Glucose in $\mathrm{mg} . / \mathrm{ml}$. HOH

Fig. 5 Linear relationship of glucose in $\mathrm{mg} . / \mathrm{ml}$. vater to the solutions optical density. 


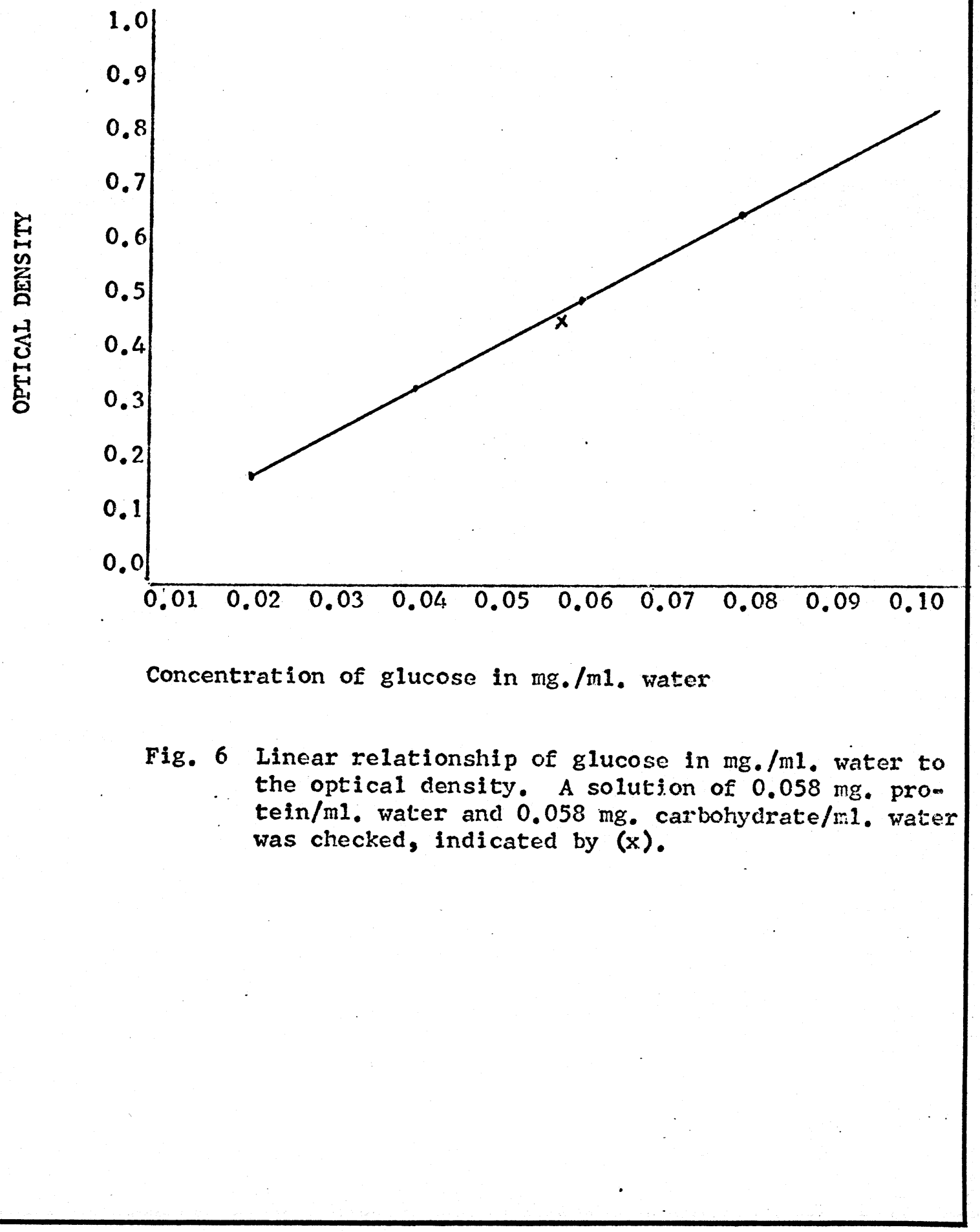




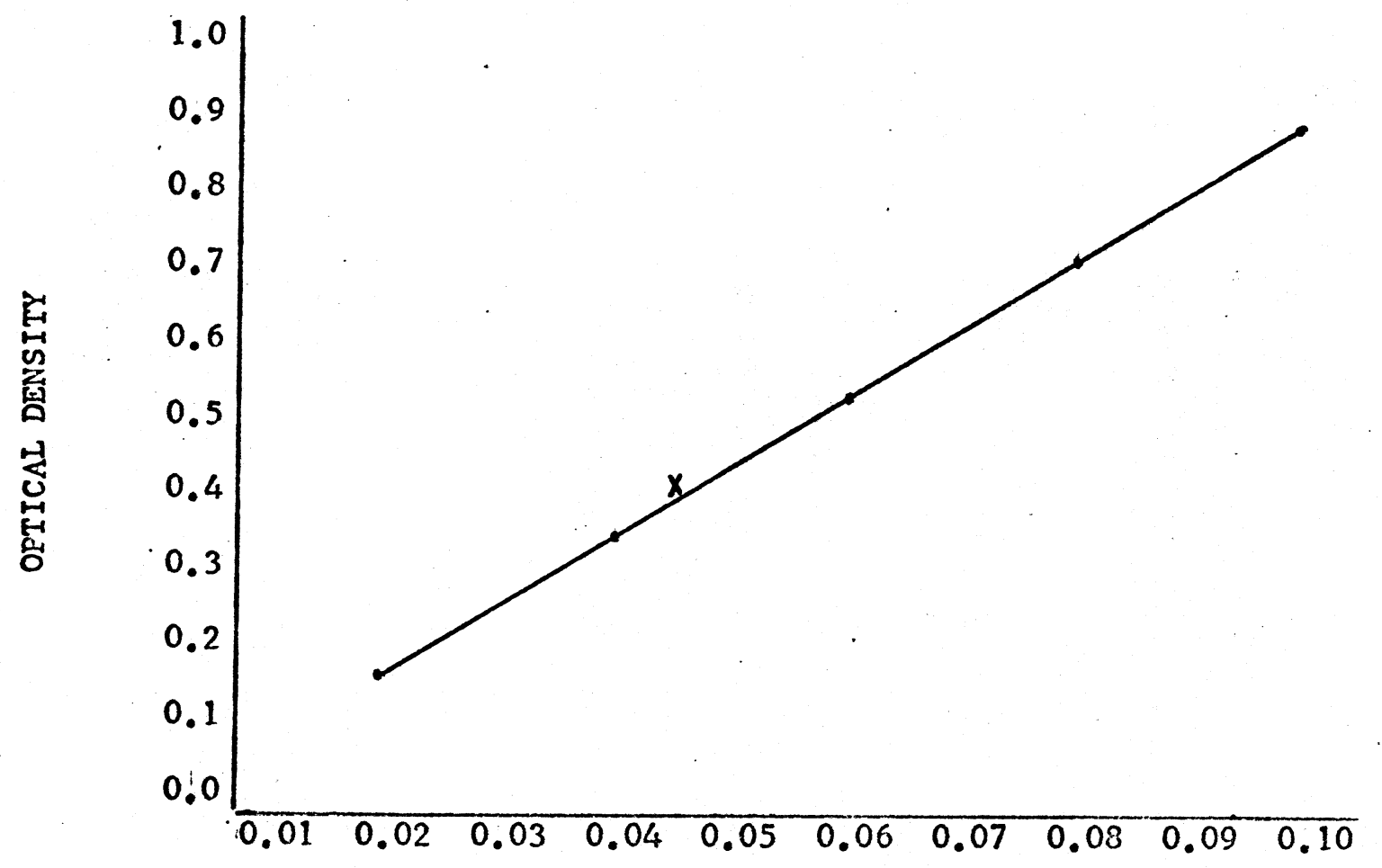

Concentration of glucose in $\mathrm{mg} . / \mathrm{ml}$. water

Fig. 7 Linear relationship of glucose in $\mathrm{mg} . / \mathrm{ml}$. water to the optical density. A solution of $0.275 \mathrm{mg}$. protein $/ \mathrm{ml}$. water and $0.045 \mathrm{mg}$. carbohydrate/mi. water was checked, indicated by $(x)$. 
Before bancing $=$ Earat

After banding $=$

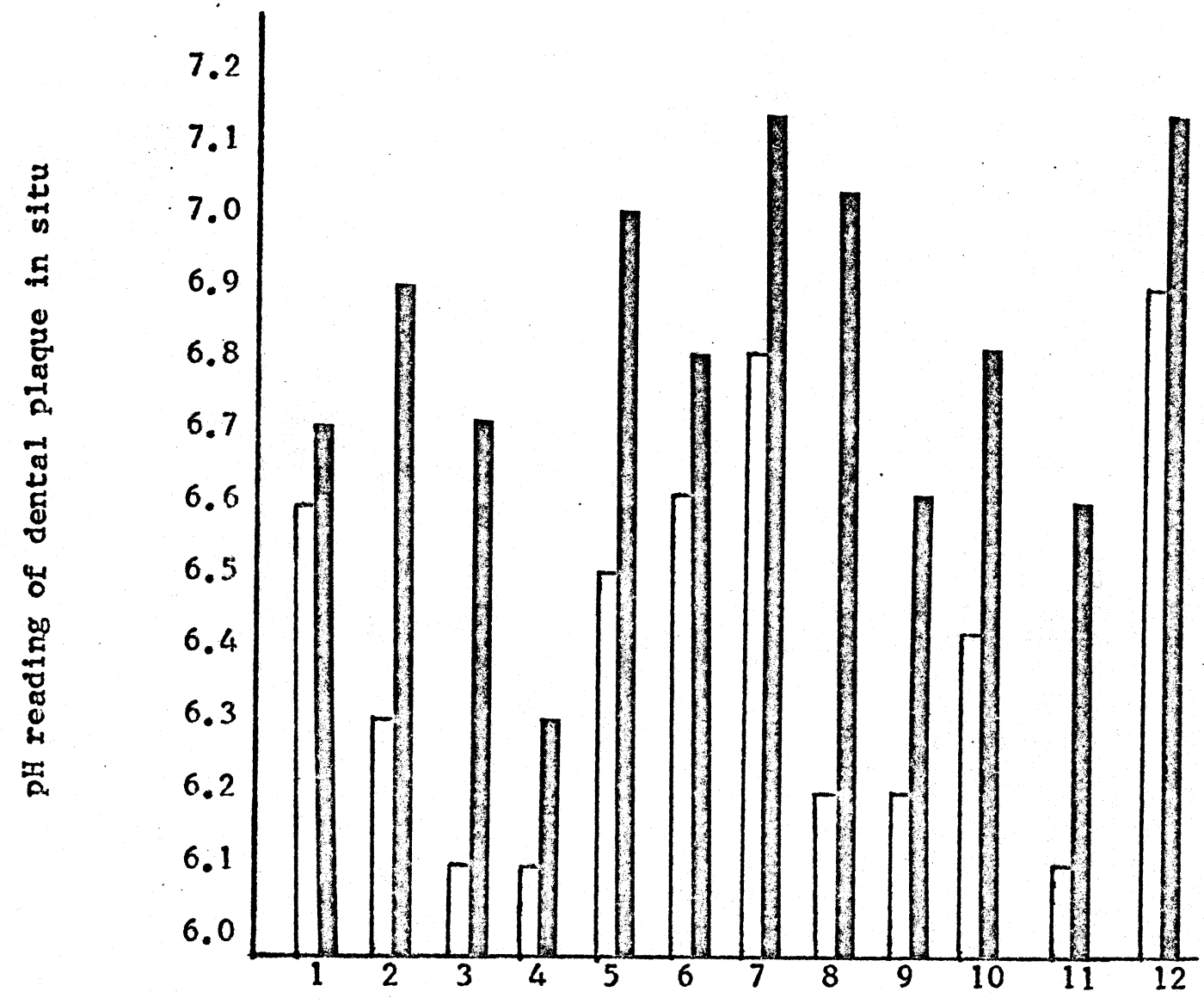

Patients in order of testing

Fig. 8 pH reading of patients before and after banding (as based on Table 3 ). 
Before banding $=\square$

After banding =

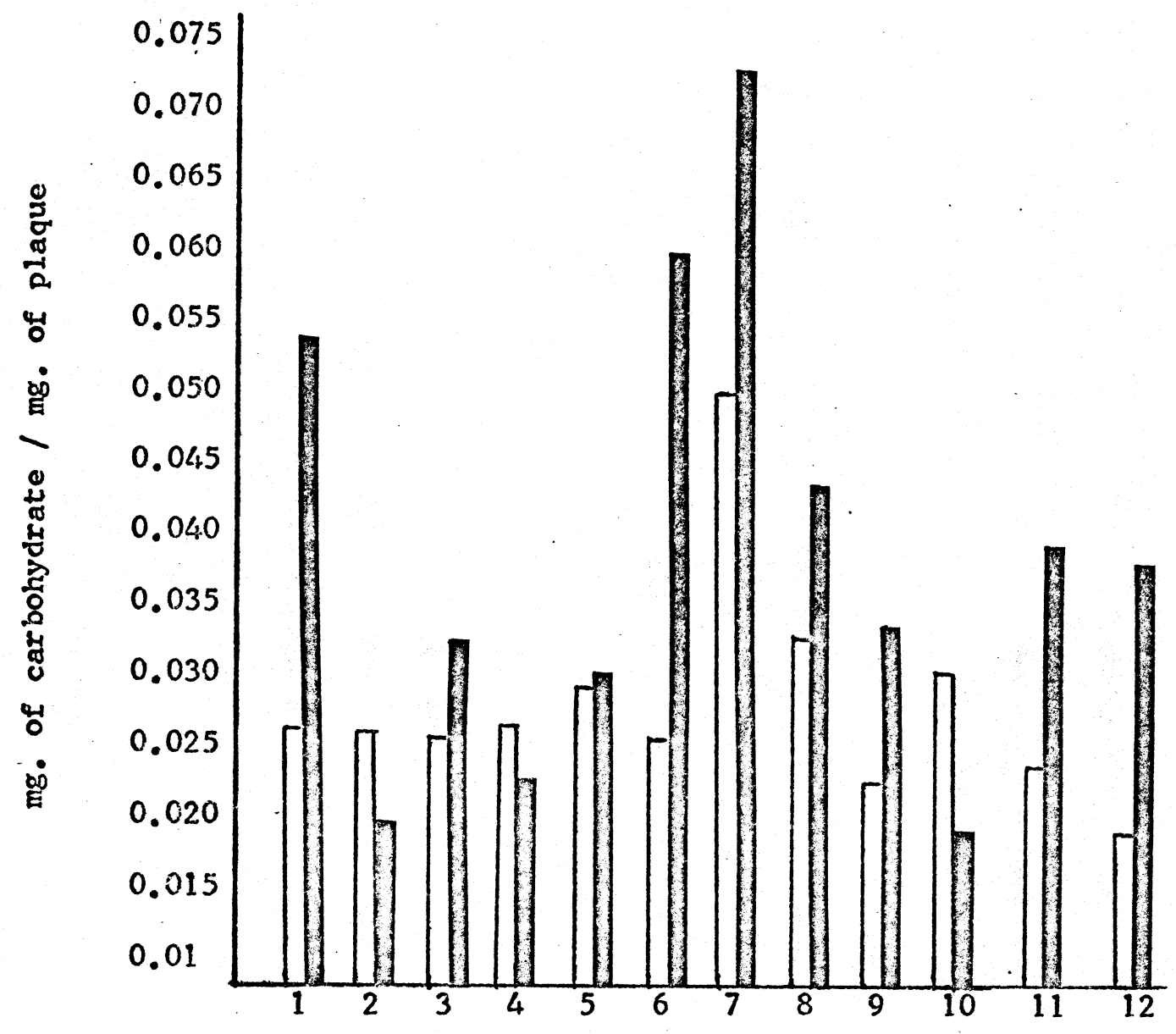

Patients in order of testing

Fig. 9 The carbohydrate content of the dental plaque before and after banding (as based on Table 3 ). 

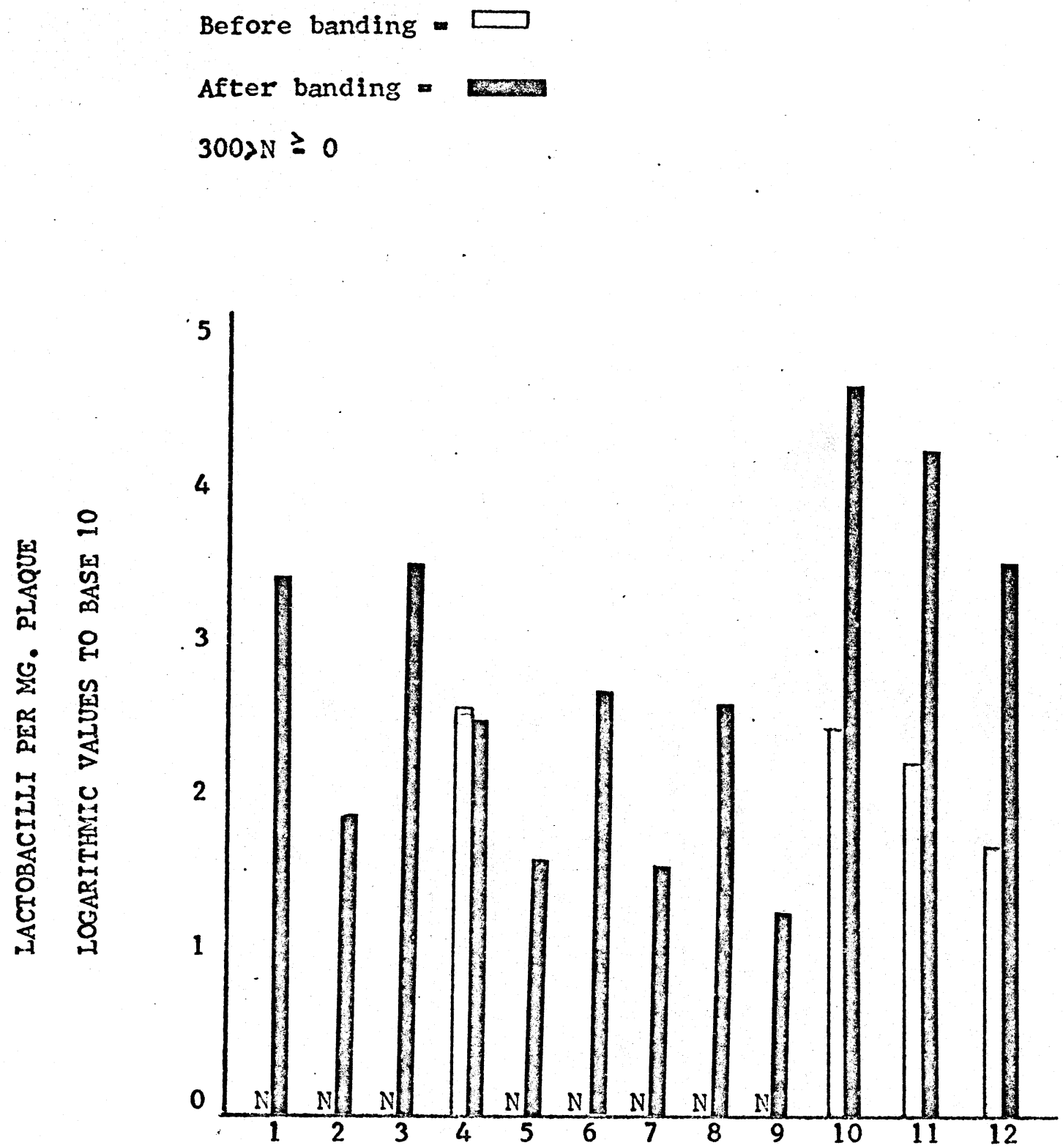

Patients in order of testing

Fig. 10 The Lactobacillus counts logarithnically expressed (as based on Table 3 ). 

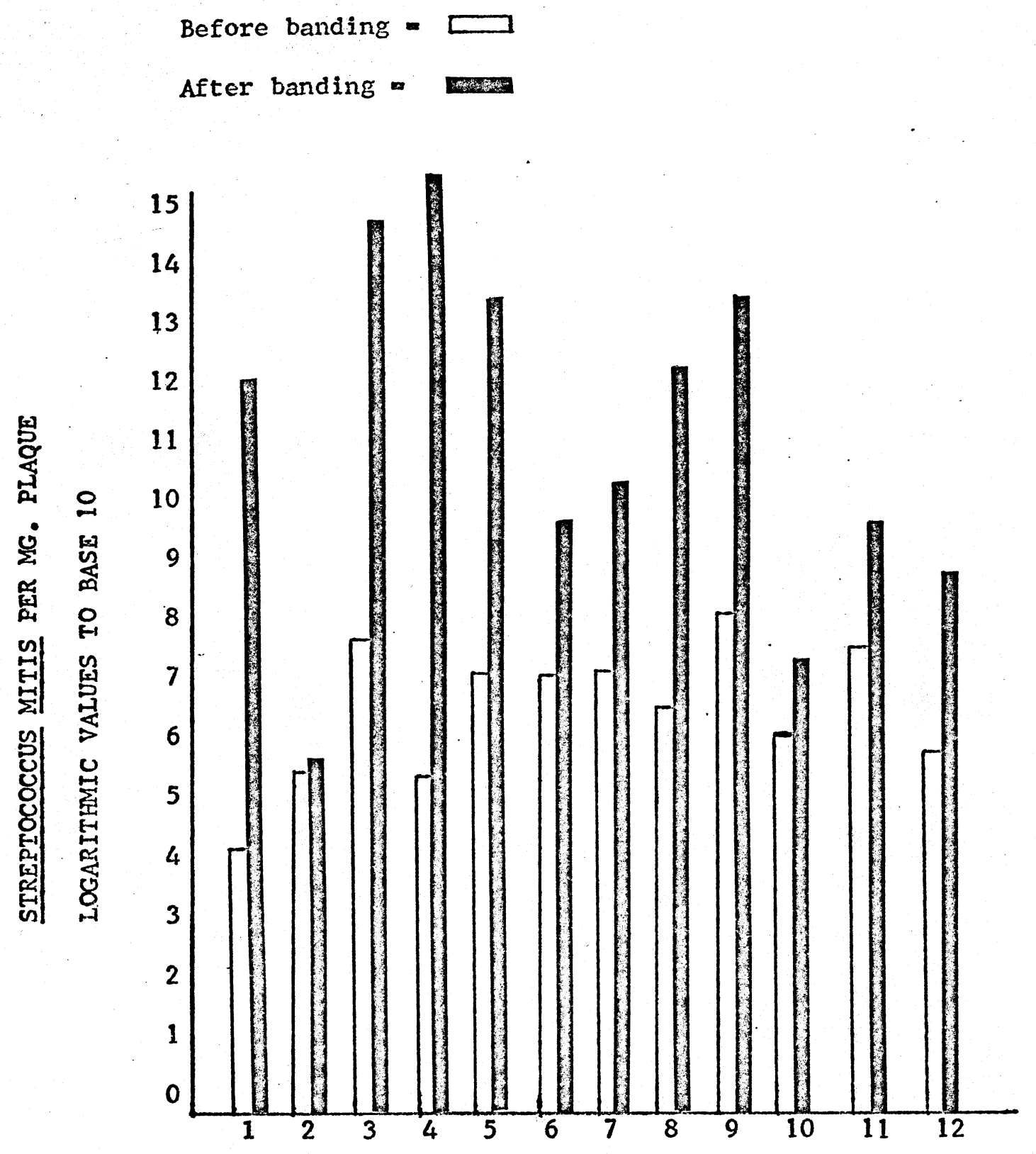

Patients in order of testing

Fig. 11 The streptococcus mitis counts logarithrically expressed (as based on Table 3 ). 


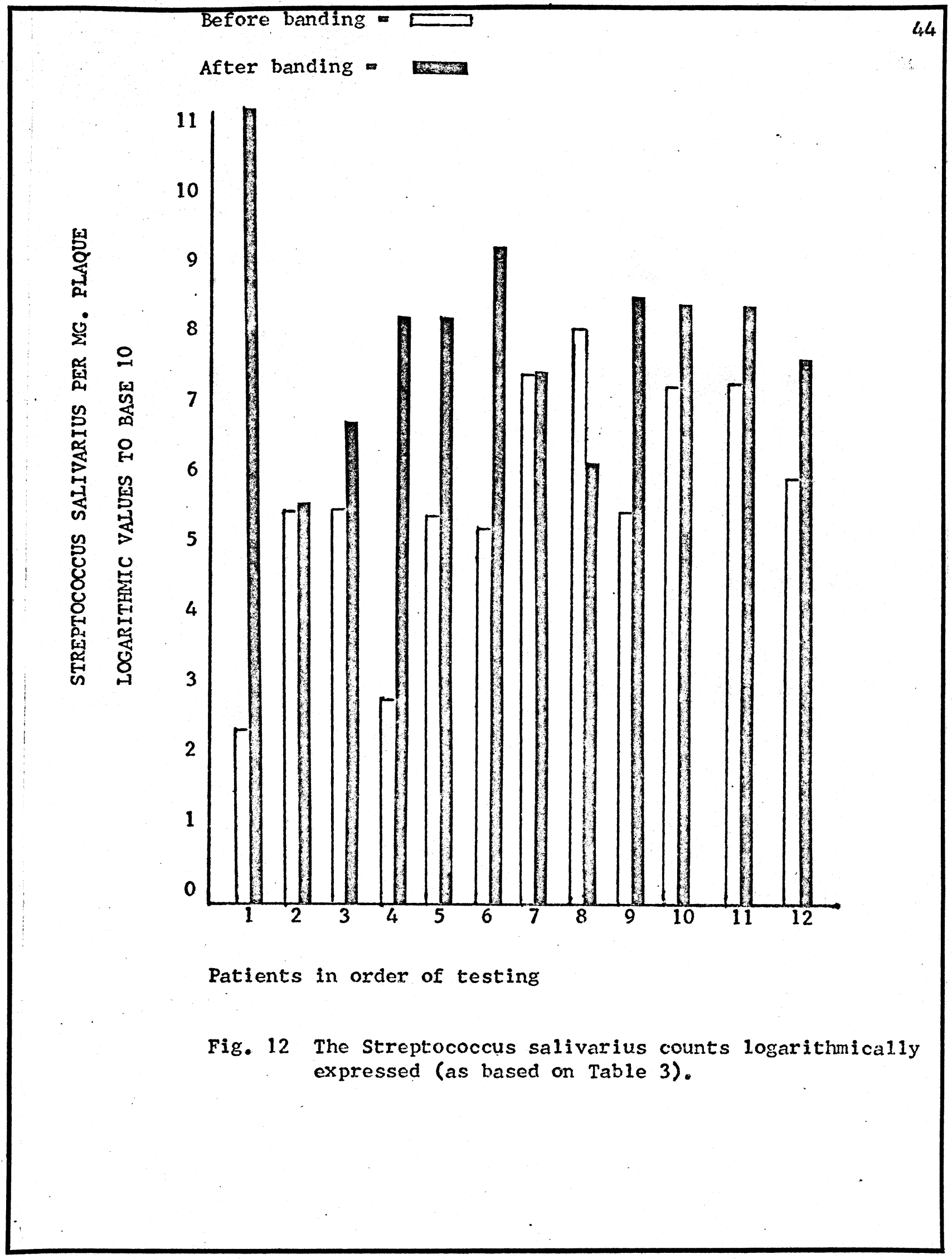


Before banding $:$

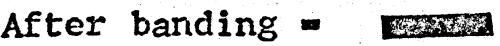

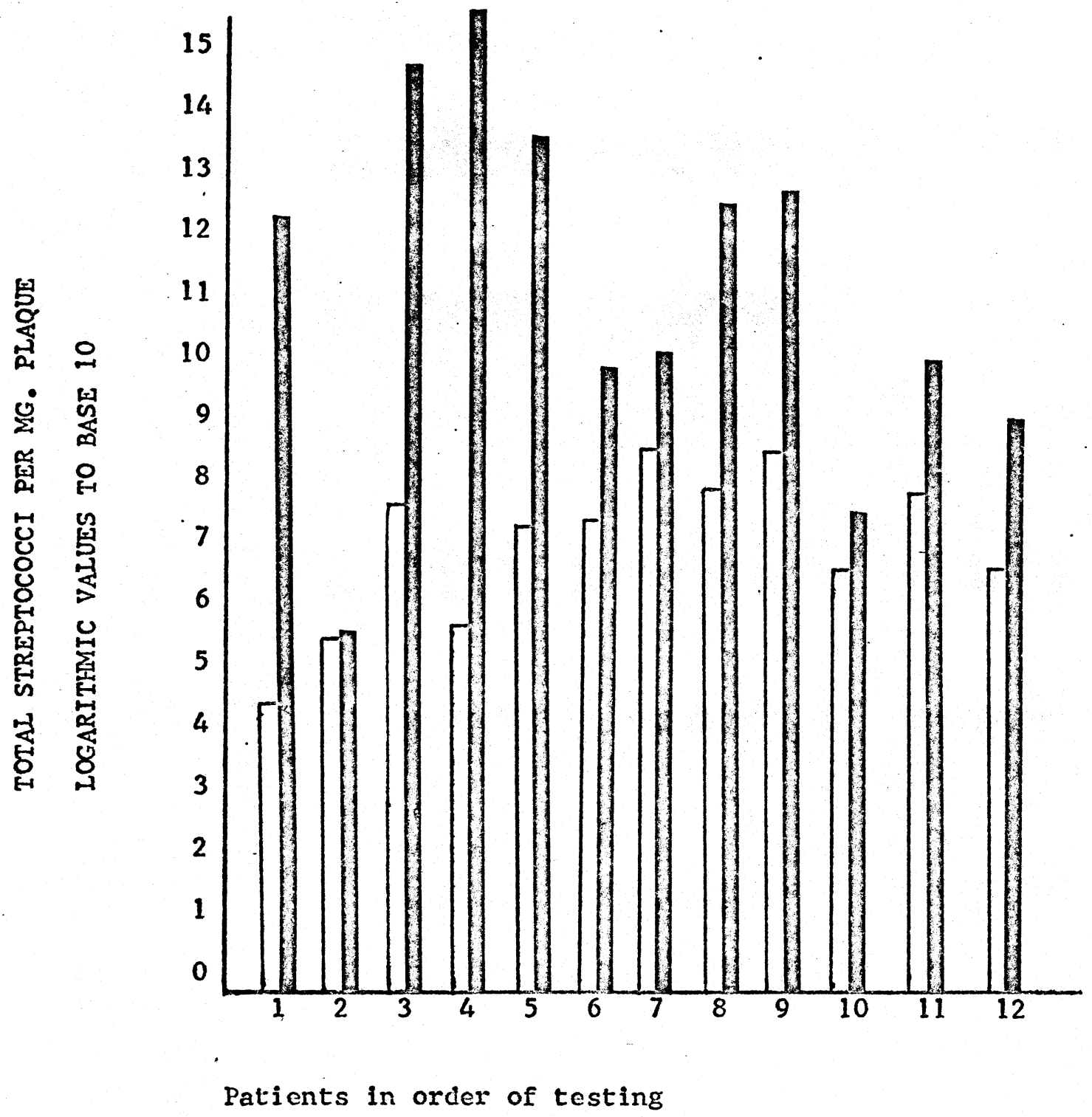

Fig. 13 The total Streptococcus counts logarithnically expressed (as based on Table 3 ). 


\section{TABLE 1}

Mean plaque content Measurenent per mg of plaque

BEFORE

$\mathrm{pH}$

6.8

0.0277

Carbohydrate

Lactobacillus

count

Streptococcus

mitis count

$1.51(10)^{14}$

$1.50(10)^{14}$

Streptococcus

Salivarius

Count

$4.35(10)^{2}$

$9.81(10)^{4}$

$9.80(10)^{4}$

0.0100

0.0377

DIFFERENCE

6.4

$$
9.80(10)^{4}
$$

AFTER
0.4
0.4

Mg of

$$
4.35(10)
$$

$$
2.28(10)^{7}
$$


TABLE 2.

STATISTICAL ANALYSIS OF PLAQUE DIFFERENCES. PER MG OF PLAQUE

$\mathbf{t}$

d

SE-

p

$\mathrm{pH}$

8.36

0.418

0.05

0.01

Mg of

Carbohydrate

2.35

0.00915

0.0039

0.05

Lactobaci11us count

6.33

9380.2

1481.5

0.01

Streptococcus mitis count

$7.89151 .6(10)^{12} 1.91(10)^{13}$

0.01

Streptococcus

salivarius count

$6.81 .79(10)^{10}$

$2.63(10)^{9}$

0.01

Total streptococci

$7.22 \quad 1.50(10)^{14} 2.09(10)^{13}$

0.01 
TABLE 3

Data (per $\mathrm{mg}$. of plaque) collected 1 week before banding, and data collected 1 month after insertion of bands and arch wires.

Patients

pH

mg of

Carbohydrate

Lactobacillus

count

Streptococcus

mitis count

Streptococcus

salivarius

count

Total

Streptococci $\underline{1}$

6.70

6.60

0!0266

0.0537

0.0267

0.0197

0.0256

0.0329

6.70

6.1

6.3

256
329

$3.33(10)^{3}$

${ }_{9.0(10)}^{\text {N.S }}$

${ }_{4.99}{ }^{\text {N.S }}(10)^{3}$

$2.18(10)^{4}$

$3.07(10)^{5}$
$4.20(10)^{5}$

$\left.\frac{4.28(10}{6.49(10)}\right)^{7}$

$4.20(10)^{4}$
$4.50(10)^{5}$

$3.06(10)^{5}$
$6.66(10)^{6}$

$\left.2.15(10)^{2.54(10}\right)_{1}^{2}$

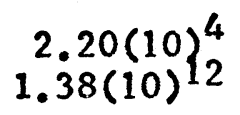

$4.31(10)^{7}$
Before

After

3

Before

After

Before

After

Before

After

Before After

Before After 
TABIE 3 (cont'd)

Data (per mg. of plaque) collected 1 week before bnading, and data collected 1 month after insertion of bands and arch wires.

Patients

$\underline{4}$

$\underline{5}$

$\underline{6}$

pH

6.30

6.10

7.00

6.52

6.80

6.60

Before

After

mg of

Carbohydrate

0.0262

0.0221

0.0272

0.0248

0.0283

0.0595

Before

After

Iactobacillus

count

$$
\begin{aligned}
& 4.68(10)^{2} \\
& 4.50(10)^{2}
\end{aligned}
$$

$1.68(10)^{N} 1$

$6.60(10)^{2}$

Before

After

Streptococcus

mitis count

$2.68(10)^{5}$
$1.12(10)^{5}$

$1.29(10)_{3}^{7}$

$1.6(10)^{7}$
$5.00(10)^{9}$

Before

After

Streptococcus

salivarius

$6.89(10)^{2}$
$1.24(10)^{8}$

$2.77(10)^{5}$
$1.68(10)^{8}$

$1.32(10)^{5}$
$1.50(10)^{9}$

Before

count

Total

streptococci

$2.69(10)^{5}$
$1.12(10)^{15}$

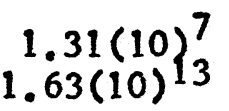

$1.61(10)^{7}$
$6.5(10)^{9}$

Before

After 
TABLE 3 (cont'd)

Data (per mg. of plaque) collected 1 week before banding, and data collected 1 month after insertion of bands and arch wires.

Patients

I

8

9

pH

7.10

6.80

7.00

6.60

6.20

Before

6.20

0.0504

mg of

Carbohydrate

0.0715

0.0310

0.0414

0.0216

0.0317

Before

After

Lactobacillus

count

$1.52(10)^{2}$

$5.33(10)^{2}$

$2.63(10)^{N . S}$

Before

After

Streptococcus

iitis count

$$
\left.2.32(10)^{2.63(10}\right)^{7}
$$

$4.63(10)^{6}$
$1.55(10)^{2}$

$1.22(10)^{8}$
$3.15(10)$

Before

After

Streptococcus

salivarius

$2.56(10)^{8}$
$2.72(10)^{8}$

$6.38(10)^{7}$
$2.84(10)^{6}$

$1.53(10)^{5}$

2. $63(10)^{8}$

Before

After

count

Tota1

streptococei

$2.34(10)\}_{0}^{8}$

$6.84(10)^{7}$
$1.55(10)^{2}$

$1.27(10)^{8}$
$3.15(10)^{12}$

Before

After 
TABLE 3 (cont'd)

Data (per $\mathrm{mg}$. of plaque) collected 1 week before banding, and data collected 1 month after insertion of bands and arch wires.

Patients

$\mathrm{pH}$

mg of

Carbohydrate

Lactobacillus

count

Streptococcus

mitis count

Streptococcus

salivarius

count

Total

streptococci
10

11

12

6.80

6.40

6.60

6.10

7.10

6.90

Before After

0.0292

0.0165

0.0231

0.0382

0.0200

0.0368

Before

After

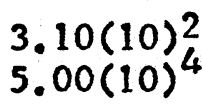

$1.63(10)^{2}$
$1.80(10)^{4}$

$6.77(10)^{1}$
$5.25(10)^{3}$

Before

After

$$
\begin{aligned}
& 1.55(10)^{6} \\
& 1.92(10)^{7}
\end{aligned}
$$

$4.57(10)^{7}$
$3.19(10)^{9}$

$8.71(10)^{5}$
$4.43(10)^{8}$

Before

After

Before

After:

$$
\begin{aligned}
& 1.27(10)^{7} \\
& 1.28(10)^{8}
\end{aligned}
$$

$1.55(10)^{7}$
$1.86(10)^{8}$

$8.94(10)^{5}$
$4.59(10)^{7}$

Before After 
APPROVAL SHEET

The thesis submitted by Dr. Jack $U$. Balenseifen has been read and approved by three members of the Graduate School Faculty.

The fInal copies have been examined by the director of the thesis and the signature which appears below verifies the fact that any necessary changes have been incorporated, and that the thesis is now given final approval with reference to content, form, and mechanical accuracy.

The thesis is therefore accepted in partial fulfillment of the requirement: for the Degree of Master of Silence.
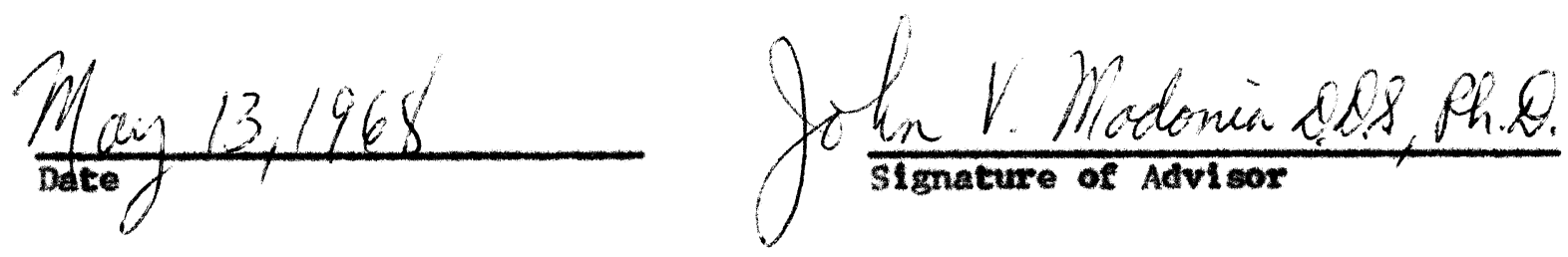